\title{
A holistic intervention program for children from low socioeconomic status families
}

\author{
Jonathan S. E. Tan ${ }^{\dagger}$, Hwajin Yang ${ }^{* \dagger}$ and Sujin Yang \\ School of Social Sciences, Singapore Management University, Singapore \\ ${ }^{*}$ Correspondence: hjyang@smu.edu.sg \\ these authors have contributed equally to this work.
}

Edited by:

Elysia Davis, UC Irvine, USA

Reviewed by:

Pilyoung Kim, University of Denver, USA

Keywords: cognitive development in children of low-socioeconomic families, holistic intervention program, family context, home environment, early intervention program

\section{A commentary on}

Family-based training program improves brain function, cognition, and behavior in lower socioeconomic status preschoolers by Neville, H. J., Stevens, C., Pakulak, E., Bell, T. A., Fanning, J., Klein, S., et al. (2013). Proc. Natl. Acad. Sci. U.S.A. 110, 12138-12143. doi: 10.1073/pnas.1304 437110

There is considerable evidence that children from families with low socioeconomic status (SES) are at risk of profound delays in cognitive development and educational achievement. Scholars and policy makers have therefore sought to identify the potential causes of these problems and to design interventions to narrow this achievement gap. With this goal, Neville et al. (2013) developed a family-based intervention (PCMC-A) to improve neurocognitive functions supporting selective attention in low-SES preschoolers. Involving both parents and children in the training, they demonstrated that the PCMC-A significantly improved nonverbal IQ, receptive language, neurocognitive functions supporting early attentional processing, parent-reported social skills, and parent-child interactions, and reduced parenting stress. Given that previous studies have focused on the training of children, it is noteworthy that Neville et al. examined factors related to not only children but also parents (e.g., parents' stress regulation and contingency-based discipline) and the home environment (e.g., parent-child interaction, parents' language use with the child, and facilitation of child attention).
Although the authors' findings are interesting and their contributions are remarkable, the family-related factors chosen for the study are far from satisfactory, as the study did not adequately consider the broader family context, which is crucial in capturing the richer dimensions of SES. Our primary goal is therefore to draw attention to the challenges posed by the family-based intervention of Neville et al. In particular, we recommend that future research consider risk factors such as personal resilience, as well as maternal and environmental factors, as they have been shown to affect cognitive development in children from low-SES families (for a review, see Bradley and Corwyn, 2002; Evans, 2004, 2006).

Specifically, resilience-a dynamic process wherein individuals display positive adaptation despite significant adversity or trauma (Luthar and Cicchetti, 2000)is a crucial index of individual differences in the fundamental adaptive system. Often overlooked, it has nonetheless been proven to be a positive moderator for many low-SES children who do well despite the odds (Knitzer and Perry, 2009). Early research on resilience-assessed by children's attachment security or social competence (Luthar and Cicchetti, 2000; Masten, 2001)—has largely emphasized the importance of personality traits and active coping strategies that help children overcome adversity and the risk factors associated with low SES (Bradley and Corwyn, 2002). Thus, future interventions should promote resilience by focusing on self-regulation skills that are essential in facilitating children's adaptive abilities, such as self-control, social competencies, and emotion regulation. In fact, the effectiveness of self-regulation has been demonstrated in various intervention programs (Greenberg, 2006; Diamond et al., 2007; Bierman et al., 2008; Raver et al., 2011).

Moreover, future family interventions must include maternal risk factors. The literature has consistently shown that maternal depression and substance abuse (e.g., cocaine, tobacco, or alcohol) have been linked with severe consequences for cognitive development (Petterson and Albers, 2001; Shankaran et al., 2007). Furthermore, because low-SES infants are generally more prone to experience these maternal risk factors than their high-SES counterparts, the consequences are usually more pronounced in children from low-SES families (Parker et al., 1988; McLoyd, 1998). Hence, it is important to screen mothers with either depressive symptoms or previous history of substance abuse. Alternatively, future family interventions should consider including a self-care program (e.g., relaxation, social skills, personal development and recreational activities, or marital adjustment), caregiving practices (e.g., co-parenting or child-care resources), or substance abuse treatment (e.g., counseling or relapse prevention), all of which are known to improve maternal mental well-being.

Finally, there is no doubt that chronic noise exposure, crowded housing (calculated by the number of people per room), substandard housing (low-quality construction or lack of privacy, cleanliness, tidiness, or children's resources), and poor neighborhood quality are prevalent among low-SES homes (for a review, see 
Evans, 2004, 2006). An increasing body of evidence suggests that these factors are an important cause of decreased cognitive functioning in children, given that they disrupt activities such as studying, exploration, and play. For instance, children exposed to transportation noise (principally aircraft) have been found to manifest significant delays in the development of reading ability when SES is controlled for (Evans and Hygge, 2007). Residential crowding has been shown to negatively affect not only child-parent interactions (Bartlett, 1998) but also verbal, perceptual, and quantitative performance during early childhood (Gottfried and Gottfried, 1984). Lastly, children from homes with irregular schedules for homework, bedtime, etc., have shown deficits in cognitive development (Petrill et al., 2004). Given the above, it is noteworthy that previous interventions such as income intervention programs and residential mobility programs-which provide low-income families with tenant-based rental subsidies-have been successful in improving schooling outcomes and reducing problem behaviors in low-SES children (Gennetian and Miller, 2002; Johnson et al., 2002). Taken together, family-based interventions require a holistic and multilevel approach that examines the extent to which a broad developmental context (i.e., individual differences combined with home and parental factors) modulates intervention outcomes for low-SES children, as these factors can increase the efficacy of programs fostering cognitive development in low-SES children.

In conclusion, given the detrimental impact of SES-a multifaceted construct-on cognitive development during early childhood, an integrative approach to intervention programs for low-SES children is warranted. In addition, understanding the specific mediators involved would improve future intervention programs by allowing greater control and precision. The concept of precision is especially critical, given the difficulty of separating the effects of low SES and multiple co-occurring variables on child development (Bradley and Corwyn, 2002). The effectiveness of early intervention programs can be further supported by the formulation of specific national and state policies tailored to address the high-risk factors that plague low-SES families, such as complications during birth, maternal mental health, and housing and neighborhood conditions. Economists have also demonstrated that increased societal investment in early intervention programs improves cognitive ability among low-SES children, which increases overall societal welfare in the long run (Heckman, 2006). Clearly then, the development and refinement of intervention programs, which can yield substantial benefits for both low-SES children and society as a whole, is essential.

\section{REFERENCES}

Bartlett, S. (1998). Does inadequate housing perpetuate children's poverty? Childhood 5, 403-420. doi: 10.1177/0907568298005004004

Bierman, K. L., Nix, R. L., Greenberg, M. T., Blair, C., and Domitrovich, C. E. (2008). Executive functions and school readiness intervention: impact, moderation, and mediation in the head start REDI program. Dev. Psychopathol. 20, 821-843. doi: 10.1017/S0954579408000394

Bradley, R. H., and Corwyn, R. F. (2002). Socioeconomic status and child development. Annu. Rev. Psychol. 53, 371-399. doi: 10.1146/ annurev.psych.53.100901.135233

Diamond, A., Barnett, W. S., Thomas, J., and Munro, S. (2007). Preschool program improves cognitive control. Science 318, 1387. doi: $10.1126 /$ science. 1151148

Evans, G. W. (2004). The environment of childhood poverty. Am. Psychol. 59, 77. doi: 10.1037/0003066X.59.2.77

Evans, G. W. (2006). Child development and the physical environment. Ann. Rev. Psychol. 57, 423-451. doi: 10.1146/annurev.psych.57.102904.190057

Evans, G., and Hygge, S. (2007). "Noise and cognitive performance in children and adults," in Noise and its Effects, eds L. Luxon and D. Prasher (Chichester: John Wiley), 549-566.

Gennetian, L. A., and Miller, C. (2002). Children and welfare reform: a view from an experimental welfare program in Minnesota. Child Dev. 73, 601-620. doi: 10.1111/1467-8624.00426

Gottfried, A. W., and Gottfried, A. E. (1984). "Home environment and cognitive development in young children of middle-socioeconomicstatus families," in Home Environment and Cognitive Development: Longitudinal Research, ed A. W. Gottfried (New York, NY: Academic Press), 57-115 doi: 10.1016/B978-0-12-293460-5.50008-0

Greenberg, M. T. (2006). Promoting resilience in children and youth. Ann. N.Y. Acad. Sci. 1094, 139-150. doi: 10.1196/annals.1376.013

Heckman, J. J. (2006). Skill formation and the economics of investing in disadvantaged children. Science 312, 1900-1902. doi: 10.1126/science. 1128898

Johnson, M. P., Ladd, H. F., and Ludwig, J. (2002). The benefits and costs of residential mobility programmes for the poor. Housing Stud. 17, 125-138. doi: 10.1080/02673030120105947

Knitzer, J., and Perry, D. F. (2009). "Poverty and infant and toddler development: facing the complex challenges," in Handbook of Infant Mental Health, 3rd Edn., ed C. H. Zeanah (New York, NY: Guilford Press), 135-159.

Luthar, S. S., and Cicchetti, D. (2000). The construct of resilience: Implications for interventions and social policies. Dev. Psychopathol. 12, 857-885. doi: 10.1017/S0954579400004156

Masten, A. S. (2001). Ordinary magic: resilience processes in development. Am. Psychol. 56, 227. doi: 10.1037/0003-066X.56.3.227

McLoyd, V. C. (1998). Socioeconomic disadvantage and child development. Am. Psychol. 53, 185. doi: 10.1037/0003-066X.53.2.185

Neville, H. J., Stevens, C., Pakulak, E., Bell, T. A., Fanning, J., Klein, S., et al. (2013). Family-based training program improves brain function, cognition, and behavior in lower socioeconomic status preschoolers. Proc. Natl. Acad. Sci. U.S.A. 110, 12138-12143. doi: 10.1073/pnas.1304 437110

Petrill, S. A., Pike, A., Price, T., and Plomin, R. (2004). Chaos in the home and socioeconomic status are associated with cognitive development in early childhood: environmental mediators identified in a genetic design. Intelligence 32, 445-460. doi: 10.1016/j.intell.2004.06.010

Petterson, S. M., and Albers, A. B. (2001). Effects of poverty and maternal depression on early child development. Child Dev. 72, 1794-1813. doi: 10.1111/1467-8624.00379

Parker, S., Greer, S., and Zuckerman, B. (1988). Double jeopardy: the impact of poverty on early child development. Pediatr. Clin. North Am. 35, 1227-1240.

Raver, C. C., Jones, S. M., Li-Grining, C., Zhai, F., Bub, K., and Pressler, E. (2011). CSRP's impact on low-income preschoolers' preacademic skills: self-regulation as a mediating mechanism. Child Dev. 82, 362-378. doi: 10.1111/j.14678624.2010.01561.x

Shankaran, S., Lester, B. M., Das, A., Bauer, C. R., Bada, H. S., Lagasse, L., et al. (2007). Impact of maternal substance use during pregnancy on childhood outcome. Semin. Fetal. Neonatal. Med. 12, 143-150. doi: 10.1016/j.siny.2007. 01.002

Conflict of Interest Statement: The authors declare that the research was conducted in the absence of any commercial or financial relationships that could be construed as a potential conflict of interest.

Received: 22 May 2014; accepted: 07 July 2014; published online: 25 July 2014.

Citation: Tan JSE, Yang H and Yang S (2014) A holistic intervention program for children from low socioeconomic status families. Front. Psychol. 5:797. doi: 10.3389/fpsyg.2014.00797

This article was submitted to Developmental Psychology, a section of the journal Frontiers in Psychology.

Copyright (c) 2014 Tan, Yang and Yang. This is an openaccess article distributed under the terms of the Creative Commons Attribution License (CC BY). The use, distribution or reproduction in other forums is permitted, provided the original author(s) or licensor are credited and that the original publication in this journal is cited, in accordance with accepted academic practice. No use, distribution or reproduction is permitted which does not comply with these terms. 